\title{
Travel Cost Budget and Ability of Urban Bus Users to Pay Considering the Income Classes in Indonesia
}

\author{
LULUSI LULUSI $^{\mathrm{a}}$ SUGIARTO SUGIARTO ${ }^{\mathrm{a}, *}$, RENNI ANGGRAINI ${ }^{\mathrm{a}}$, FADLULLAH APRIANDY $^{\mathrm{a}}$, \\ ARIF FADHURROZI ${ }^{\mathrm{b}}$, MUHAMMAD RUSDI ${ }^{\mathrm{c}}$, DEFRY BASRIN $^{\mathrm{d}}$ \\ a. Department of Civil Engineering, Universitas Syiah Kuala, Banda Aceh 23111. \\ b. Alumni, Department of Civil Engineering, Universitas Syiah Kuala, Banda Aceh 23111. \\ c. Remote Sensing and Cartography Laboratory, Universitas Syiah Kuala, Banda Aceh 23111. \\ d. Department of Civil Engineering, Universitas Samudra, Langsa 24415.
}

KEYWORDS: Trans Koetardja, Bus reform, Travel cost budget, Ability to pay, Reveal preference, Indonesia

\begin{abstract}
The Bus Reform policy known as Trans Koetardja was adopted and implemented in Banda Aceh of Indonesia in early 2018 to promote bus ridership and to specifically mitigate the dependency on private means of transportation. This system is presently being run as a trial and free of service charge through the subsidy provided by the government of Aceh with the amount being spent projected to escalate by the year 2020 due to expansion in the number of bus lines. There is, however, the plan to introduce bus fare to ease the burden of subsidies on the government but most of those engaged in the ridership are generally students and people from low-income households. Therefore, there is the need to determine an appropriate charge or tariff based on the household's ability to pay (ATP), especially with the focus on the need for low-income people to sustain the subsidy for their daily travel. This study was conducted to determine the ability to pay (ATP) for bus users through the use of travel cost budget (TCB) which is defined as the
\end{abstract}

maximum money allocated by a household for transportation within a month as a constraint. The TCB was classified based on income classes into low-income and medium-high income to ensure simplicity. The research was conducted in 2019 by collecting 450 samples from three Trans Koetardja lines using reveal preference (RP) survey after which Ordinary Least Square (OLS) method was adopted to identify the factors significantly contributing to TCB based on the income classes. Moreover, the ATP for each income class was also determined using the household budget method. The empirical results from the OLS showed the TCB usually allocated by medium-high income households is slightly different from those with low-income as observed with 0.306 million IDR/ month (20.85 USD/month) and 0.208 million IDR/month (14.17 USD/ Month) while the predicted ATP was 7,397 IDR/trip (0.5 USD/trips) and 2,259 IDR/trip (0.15 USD/trips), respectively. It is, however, important to note that 1 USD $=14,677.73$ IDR. Furthermore, the factors observed to be influencing the variation in TCB include age, monthly income, gender, and the number of private cars or motorcycles owned within the household.

\section{INTRODUCTION}

Traffic congestion has become a serious hindrance to economic development in several Indonesian urbanized cities including Banda Aceh which is the capital of Aceh Province in the western part of the country. This was reported to be due to rapid urbanization and high dependence on private modes of transportation through cars and motorcycles (Saleh et al., 2017). The uncontrolled increase in personal mobility has, therefore, led to unmaintainable externalities and also significantly influencing the quality of life within the city due to several factors such as the escalation of travel time, additional fuel consumption, and deterioration of the city environment, especially noise and emission level. Several studies have, however, been conducted in relation to congestion in Jakarta (Sugiarto et al., 2014a; 2019), Rumania (Tosa et al., 2018a; 2018b), and Banda Aceh (Saleh et al., 2017; Anggraini et al., 2017).

The traffic congestion problem has motivated the government of Aceh to implement a bus reform policy known as the Trans Koetardja in the year 2016 to deal with the poor public transport services in the city. It was also directed towards providing support for the government's plan to replace the conventional public transport system with a more convenient

\footnotetext{
* Corresponding author E-mail: sugiarto@unsyiah.ac.id
}

and affordable bus system using new technology and system operation. The Trans Koetardja is a system which involves the use of busses with a capacity of 60 passengers and an air conditioner to provide more comfort for the passengers (Saleh et al., 2019) and a total of 52 is currently being operated by the government to serve 5 bus lines within the city. However, previous studies by Sugiarto et al., (2019) and Adris et al., (2014) have explored the effectiveness of this system in reducing autos dependency and improving mobility for lowincome people, especially students. The policy is observed to be widely accepted by the public but they are somehow not willing to use the buses due to limited lines and feeders. This system was implemented like the Bus Rapid Transit (BRT) and approved by researchers to be an effective public transport method with a remarkable prospect for Jakarta and Yogyakarta (Joewono et al., 2007; Nursyamsu., 2018). Moreover, the provision of an affordable public transport system has also been reported to be affecting congestion-related factors as observed with the reduction in $\mathrm{CO} 2$ emissions, increase in fuel use efficiency, and more equitable mobility (Sugiarto et al., 2014; 2019).

The Trans Koetardja has been operating for three years without any charge based on government subsidy but there is a plan to introduce an appropriate charge or tariff in order to ease the burden on the government and with due consideration for low-income people. Therefore, there is the need to determine an appropriate charge or tariff based on the 


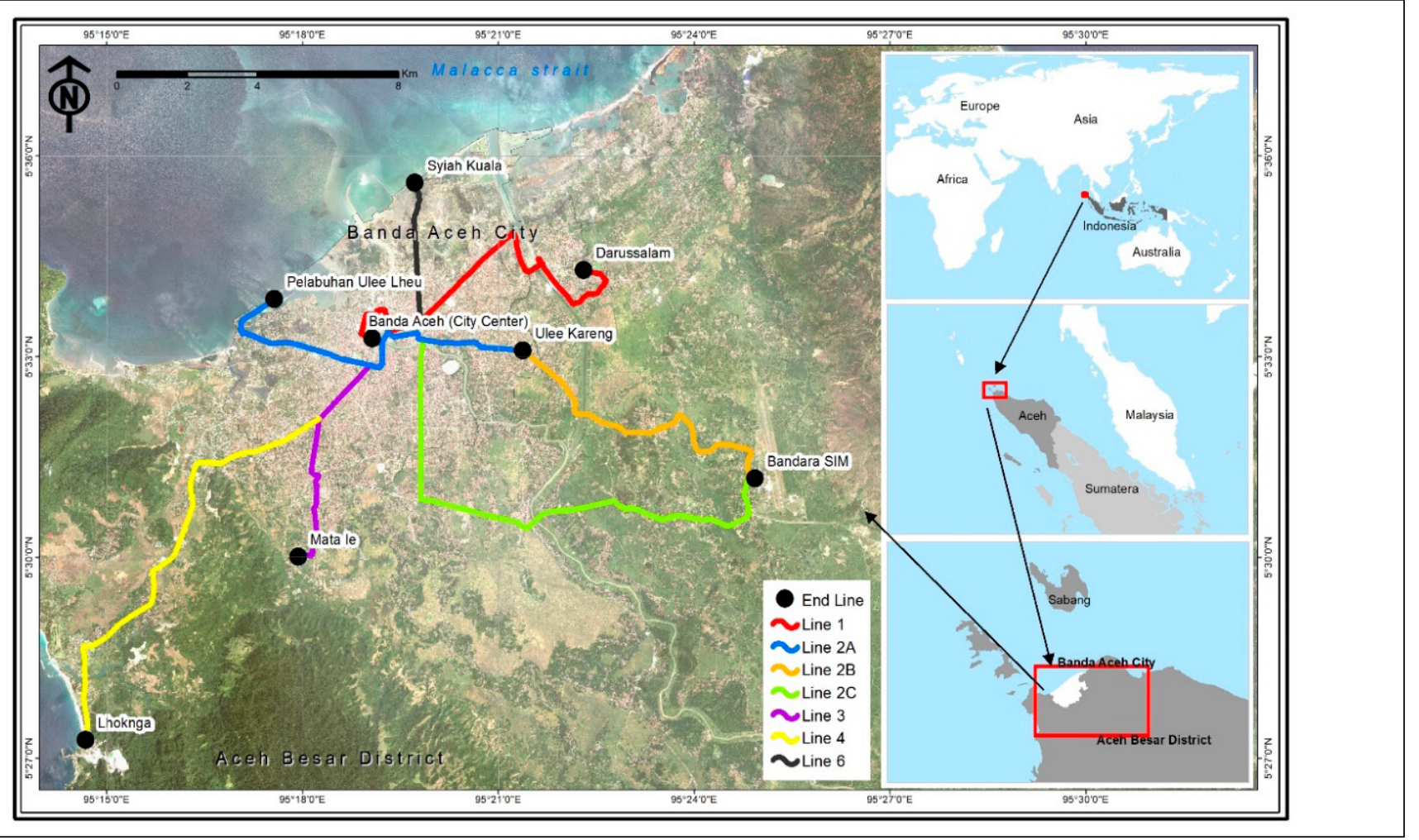

Figure 1: Area of study (line 1, 2b, and 3)

household's ability to pay (ATP), especially with the focus on the need for low-income people to sustain the subsidy for their daily travel. This study was conducted to determine the ability to pay (ATP) for bus users through the use of travel cost budget (TCB) which is defined as the maximum money allocated by a household for transportation within a month as a constraint. The TCB was classified based on income classes into low-income and medium-high income to ensure simplicity. The research was conducted in 2019 by collecting 450 samples from three Trans Koetardja lines using reveal preference (RP) survey after which Ordinary Least Square (OLS) method was adopted to identify the factors significantly contributing to TCB based on the income classes. Moreover, the ATP for each income class was also determined using the household budget method. The remaining aspects of this research are sectioned into several parts and these include material and methods, results, and discussion while the conclusion is presented at the end.

\section{MATERIALS AND METHODS}

\subsection{Materials}

The Reveal Preference (RP) method was used to collect relevant datasets using the questionnaire adopted from the previous transport survey approach proposed by Sugiarto et al. (2014b, 2019). A total of 450 paper-pencil questionnaires were distributed and filled by the users of the busses by the enumerator in lines $1,2 \mathrm{~b}$, and 3 as illustrated in Figure 1. Line 1 was observed to be the most congested trunk within peak hour services because it connects the Universitas Syiah Kuala which is the oldest university in the region with the city center of Banda Aceh which is a capital city in Aceh province, Indonesia as shown in Figure 1.

The data was collected from targeted respondents which were Trans Koetardja users in the three previously mentioned lines in April 2019 using questionnaires. The questions focused on social-economic characteristics such as age, gender, income, social status, monthly income, monthly travel cost budget, and vehicle ownership as well as the mobility attrib- utes such as the mode used, frequency of using the public mode, frequency of using the private mode, the purpose of travel, and the reason for using Trans Koetardja on the day the questionnaire was distributed. The summary of the survey is, however, presented in Table 1. It is important to note that the government set the bus fare to be free as a trial run for the reform policy since 2016 but considering a reduction in the subsidy, particularly for high-income households. This has led to a recent campaign by the government to implement a flat bus fare estimated at 5,500 IDR/trip (0.37 USD/trip) leading to the assumption of monthly transport cost based on the daily traveling of citizens including those using public and personal transport modes.

\begin{tabular}{ll}
\hline Descriptions & Details \\
\hline The date of the data collection & April 2019 \\
\hline The area of study & Banda Aceh, Indonesia \\
\hline Data collection method & $\begin{array}{l}\text { On-board survey based on paper- } \\
\text { pencil direct interviews collected by } \\
\text { the enumerator }\end{array}$ \\
\hline Sampling size & \begin{tabular}{l}
450 samples \\
\hline Socio-economic attributes
\end{tabular} \\
$\begin{array}{l}\text { Gender, age, education, occupation, } \\
\text { monthly income, monthly travel } \\
\text { expenditure, housing owned status, } \\
\text { household member, motorcycle } \\
\text { ownership, car ownership. }\end{array}$ \\
$\begin{array}{l}\text { Mode use, public transportation } \\
\text { use, frequency of daily public mode } \\
\text { usage, willingness to use public } \\
\text { transport, travel destination, } \\
\text { the reason to use modes of } \\
\text { transportation. }\end{array}$ \\
\hline
\end{tabular}

Table 1. Summary of the questionnaire survey.

As summarized in Table 1, the questionnaires were distributed to the respondents selected based on the criteria that 
they are 17 years and older using the bus at least 3 times a week due to the assumption of difficulty and inconsistency attached to the ability of younger people to provide responses, particularly in dealing with the allocation of monthly transport cost. The passengers that met these requirements were selected as target respondents and asked for their willingness to contribute to this study.

The socio-economic and travel behavior attributes are illustrated in Table 2 with the female gender observed to be dominant by constituting $70 \%$ of the total respondents and this means they use the buses frequently more than males. This is quite different from the findings of the previous study by Saleh et al (2019b) which showed the gender distribution to be somewhat slanted towards the males with approximately $50.7 \%$. It is, however, important to note that there is a need to update the actual gender distribution of the bus users in future studies due to the incapability of this research to show the actual numbers. Moreover, the dataset presented in Table 2 showed the young people and housewives were more predominant as indicated by the $47.8 \%$ and $38.4 \%$ contributed to the total respondents, respectively. The young people were also observed to be more likely to use Trans Koetardja compared to older ones as shown by $47.8 \%$ of the users found to be between $18-40$ years old. It was also discovered that most of the respondents have senior high school certificates as their highest level of education followed by university graduates and college education while a total of $40 \%$ indicated they are government and private employees. Moreover, $40 \%$ were categorized as low-income based on the classification of Saleh et al. (2016) which showed low-income households to be those with monthly income less than 4 million IDR/ month and high-medium income households with income higher or equal to 4 million IDR/month.

\begin{tabular}{|c|c|c|}
\hline Attribute Item & Detail of Item & $\begin{array}{l}\text { Share of Sample } \\
\qquad(\mathrm{N}=\mathbf{4 5 0 )}\end{array}$ \\
\hline \multirow[t]{2}{*}{ Gender } & Male & $30.7 \%$ \\
\hline & Female & $69.3 \%$ \\
\hline \multirow[t]{5}{*}{ Age } & $18-29$ years & $16.7 \%$ \\
\hline & 30-39 years & $31.1 \%$ \\
\hline & $40-49$ years & $32.1 \%$ \\
\hline & $50-59$ years & $18.4 \%$ \\
\hline & 60 years or more & $1.6 \%$ \\
\hline \multirow[t]{3}{*}{ Education } & Senior High School & $55.3 \%$ \\
\hline & College & $16.4 \%$ \\
\hline & University / Bachelor & $28.3 \%$ \\
\hline \multirow[t]{5}{*}{ Social Status } & Government Employee & $11.6 \%$ \\
\hline & Private Employee & $29.3 \%$ \\
\hline & Retired & $6.0 \%$ \\
\hline & Trader & $14.7 \%$ \\
\hline & Housewife & $38.4 \%$ \\
\hline \multirow{4}{*}{$\begin{array}{l}\text { Monthly } \\
\text { income (IDR) }\end{array}$} & Less than 1 million IDR (MIDR) & $9.1 \%$ \\
\hline & MIDR 1- 2.9 & $30.9 \%$ \\
\hline & MIDR 3- 4.9 & $51.3 \%$ \\
\hline & More than 5 MIDR & $8.7 \%$ \\
\hline
\end{tabular}

Table 2. Socio-economic distributions.

The mobility attributes presented in Table 3 showed 96\% of the respondents use Trans Koetardja as the representative mode while the others frequently use online public transport and conventional public mode known as "labi-labi". Moreover, the new system is being used for more than 3 days a week as reported by over $90 \%$ while $80 \%$ showed their purpose of traveling at the time the questionnaires were distributed was to get to work and go shopping.

\begin{tabular}{llc}
\hline Attribute Item & Detail of Item & $\begin{array}{c}\text { Share of Sample } \\
\text { (N=450) }\end{array}$ \\
\hline Public Transport Used & Trans Koetardja & $96.2 \%$ \\
& Online Public Transport & $0.8 \%$ \\
& "Labi-Labi" & $3.0 \%$ \\
\hline Frequency of using & 1-2 days a week & $7.3 \%$ \\
the public mode & 3-4 days a week & $35.0 \%$ \\
& 5 days a week or more & $57.7 \%$ \\
\hline Purposes of traveling & Work & $36.9 \%$ \\
& Shopping & $43.6 \%$ \\
& Pick up \& drop at school & $1.1 \%$ \\
& Social & $10.4 \%$ \\
& Entertainment & $8.0 \%$ \\
\hline
\end{tabular}

Table 3. Mobility attributes distributions.

\subsection{Methods}

A model was designed using multiple linear regression to determine the significant factors contributing to the household travel cost budget (TCB) previously described as the maximum amount of money households are willing to allocate for their transportation within a month and usually stated in Rupiah/month (Sugiarto et al., 2014b; 2020b). The exogenous variable used includes the socioeconomic and daily travel attributes as well as the observed TCB which were later regressed to the endogenous variables. The regressors and their variables are, however, presented as follows.

1. Male dummy 1 , otherwise 0 .

2. Age (years)

3. Income (million IDR/month).

4. Housing owned dummy, Otherwise 0.

5. Has Driving License Dummy 1, Otherwise 0

6. The number of private vehicles owned (unit).

7. Travel Cost (million IDR/month)

According to Jenkinds and Quintana-Ascencio (2020), research conducted based on regressions analysis requires a sample size larger than 25 while Roscoe (1975) in Sekaran and Bougie (2016) also proposed the following rules of thumb in determining sample size. (1) Sample sizes larger than 30 and less than 500 are appropriate for most research, (2) a minimum sample size of 30 is necessary for each category where samples are to be broken into subsamples such as males/females, juniors/seniors, etc., (3) multivariate research including multiple regression analyses require sample size which is several times, preferably ten times or more, as large as the number of variables in the study, and (4) simple experimental research with tight experimental controls such as matched pairs, etc. needs the small size of 10 to 20 to be successful. Therefore, 7 variables were used in this study and this means 10 times 7 is equal to 70 samples. Moreover, 450 samples have been discovered to be valid enough for regression analysis, therefore, a minimum sample size of 30 was used fulfilled for each gender category as indicated by $30.7 \%$ x 450 which is approximately 139 samples. It is also important to note that the actual data on the distribution of the individual socio-demographics passengers was not available as previously mentioned in section 2.1. The approximated sample size used in this study was, however, assumed to have the ability to offer more accuracy and validity. 
The TCB model used OLS as the modeling approach using numerous steps such as data preparation, calibration, Goodness of Fit (GoF) indices tests, establishing the final model, and revealing the statistical inference of the final model as illustrated in Figure 2. Meanwhile, the TCB was formulated using multiple linear regression based on the assumption that an experiment consisting of exogenous variables such as $\mathbf{Y}=\left\{\mathrm{Y}_{\mathrm{i}}\right\}$ has different values of independence variable $\mathbf{X}$. Moreover, an experiment with a stochastic nature has been reported to have different values of $Y_{i}$ for the same value of $\mathrm{X}_{\mathrm{i}}$ as observed in the detailed information presented in (Ortuzar \& Willumsen, 2014). $f_{i}(\mathrm{Y} \mid \mathrm{X})$ was used to represent the probability distribution of $Y_{i}$ for a given value $X_{i}$ and this makes it possible to have a different function $f i$ for each value of $\mathbf{X}$.

Assuming the probability distributions $f_{i}(\mathrm{Y} \mid \mathrm{X})$ have the same variance $\sigma^{2}$ for all values of $\mathbf{X}$, a straight line known as the true regression line was formed with the means value of $\mu i=E(Y i)$ and specified in equation (1) where the population parameters $\alpha$ and $\beta$ used to define the line are estimated from the observed data set.

(1) $E\left(Y_{i}\right)=\alpha+\beta X_{i}$

The random variables $\mathbf{Y}$ are statistically independent, and it is sometimes convenient to describe the deviation of $Y_{i}$ from its expected value as the error term $\varepsilon_{i}$. Therefore, it is possible to rewrite equation (1) as:

(2) $Y_{i}=\alpha+\beta X_{i}+\varepsilon_{i}$

It can also be written for multiple linear forms as:

(3) $Y_{i}=\alpha+\beta_{1} X_{1}+\beta_{2} X_{2}+\ldots+\beta_{n} X_{n}+\varepsilon_{i}$

The scale parameters of $\alpha$ and $\beta_{1}, \beta_{1}$ and $\beta_{n}$ were calibrated using data set observed from the survey and one common method of achieving this is through Ordinary Least Square (OLS) while the STATA statistical software was used for the calibration model.

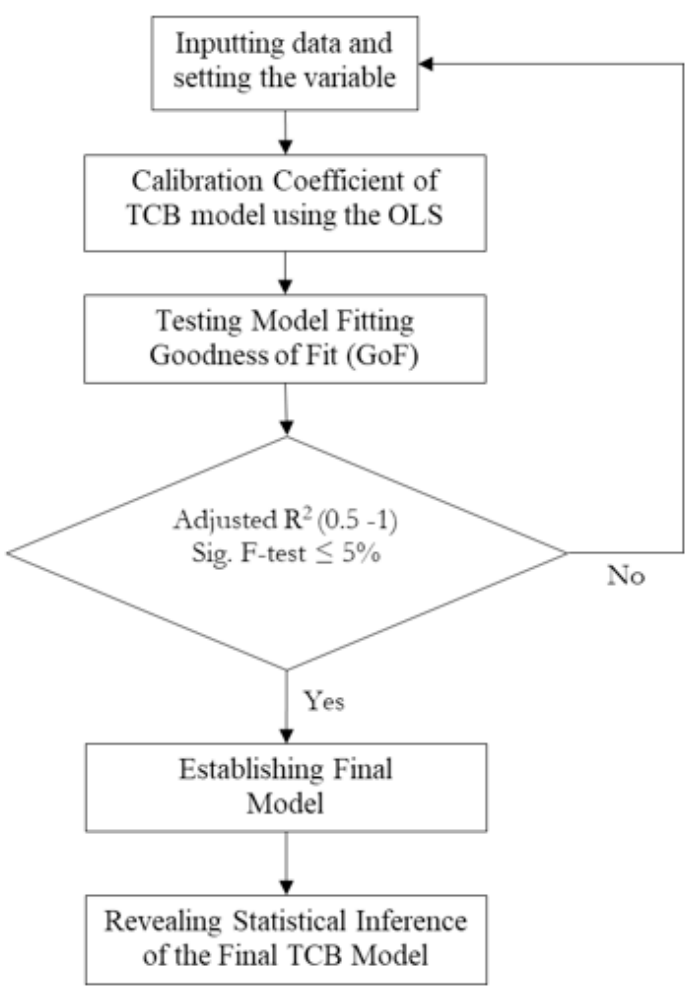

Figure 2. The Procedures of Modeling the TCB using OLS.
Several Goodness of Fit (GoF) indices including the coefficient of determination or adjusted $\mathrm{R}^{2}$ were calculated to clarify the fit of the TCB models. This coefficient is defined as the ratio of explained to total variation which is limited to 1 to represents perfect explanation and 0 for no explanation at all while the intermediate values are interpreted as the percentage of the total variation explained by regression (Ortuzar \& Willumsen, 2014; Washington et al., 2020). Moreover, F-test was used to test the hypothesis involving a linear restriction between several estimators at a 5\% significant level while those with a specific estimator or scale parameters coefficient were tested using a t-test with $10 \%$ or lower significant error.

The household budget method as defined in the following equation was applied to calculate the average ATP based on the average value of TCB for each income class.

$$
\text { (4) } \mathrm{ATP}=\left(\mathrm{I} \cdot \mathrm{P}_{\mathrm{p}} / \mathrm{F}_{\mathrm{r}}\right)
$$

Where, ATP is the ability to pay in passenger/trip, I is monthly income in IDR/month, Pp is the percentage of TCB allocated for public transport in IDR/month, and Fr is the frequency of using public transport in a month.

\section{RESULTS AND DISCUSSION}

\subsection{Travel cost budget (TCB)}

The distribution of TCB as a dependent variable presented in Figure 3 estimated the average value for the low-income household to be 1.62 million IDR/month or $21 \%$ of the monthly income while the medium-high income had approximately 4.3 million IDR/month or $31 \%$. The Trans Koetardja users were averagely observed to have a high percentage of TCB share at approximately $32 \%$ and this means transportation is significantly expensive in the city. This is in line with the findings of Sugiarto et al. (2014b) which showed the average TCB in Jakarta was between 21-24\% to indicate a higher share of the household income was for transportation. It is also important to note that having TCB higher than $10 \%$ of income indicates transportation is expensive in the country.

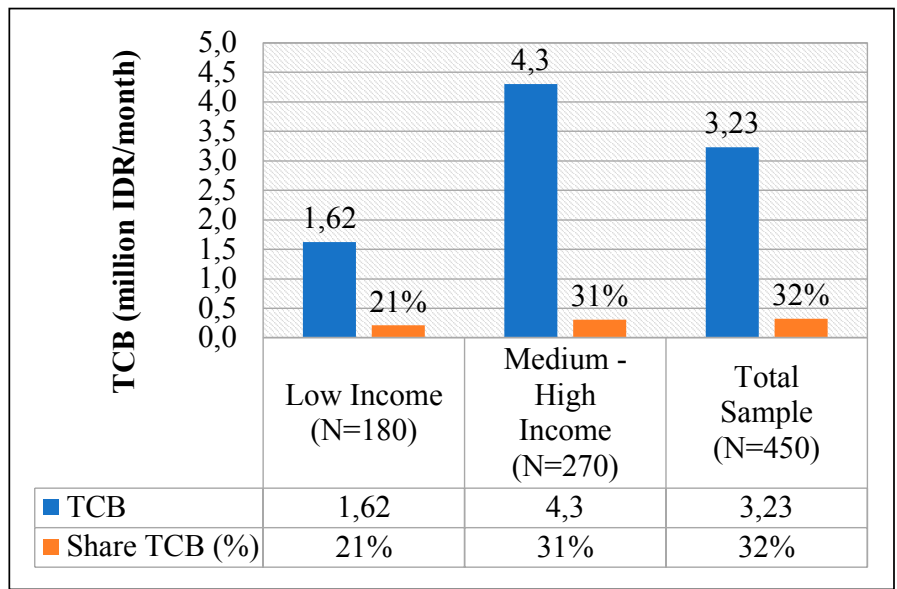

Figure 3. Travel cost budget distribution.

\subsection{Ability to Pay (ATP)}

The distribution of ATP in relation to householder's TCB across income classes is presented in Figures 4 and 5 and the average value across all the groups was estimated to be 10,000 IDR/trip (0.68 USD/trip). Meanwhile, low-income households were found to have ATP 7,000 IDR/trip (0.48 USD/ trip) while medium-high income had higher value estimated at 12,000 IDR/month (0.82 USD/trip). It is, however, important to note that the low-income households had higher ATP 
than the 5,500 IDR/trip (0.37 USD/trip) planned to be implemented by the government. This means low-income households have the ability to afford the bus fare proposed by the government despite the 1,500 IDR/trip (0.1 USD/trip) difference and they also have approximately 1,600,000 IDR/month (109.1 USD/month) TCB share which is $21 \%$ of their income budgeted for transportation. This class was also observed to have $10 \%$ less money available for trips when compared to the medium-income class. Moreover, it was discovered that the ATP for medium-high income households was 12,000 IDR/ month (0.82 USD/trip) and this is more than twice the fare proposed by the government and almost doubled the value recorded for low-income households.

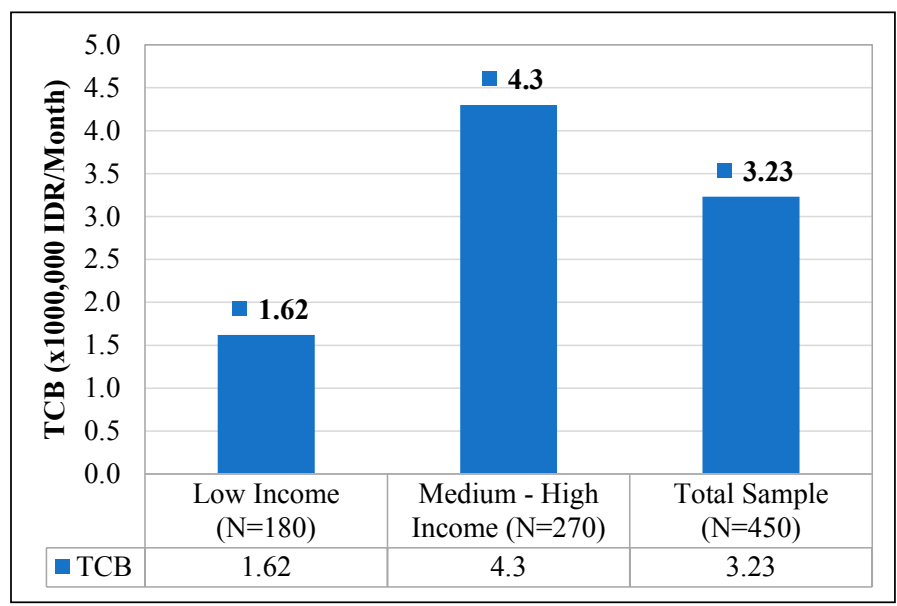

Figure 4. The TCB distributions.

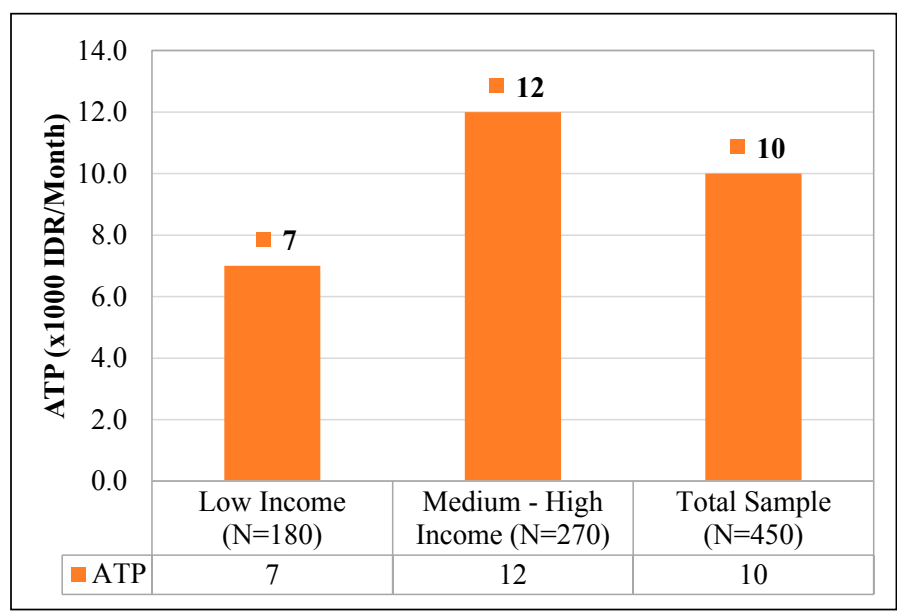

Figure 5. The ATP distributions

\subsection{Factors affecting TCB}

The effect of calibrated scale parameters on TCB across household income groups was determined by applying simple multiple regression analysis and the results are presented in Tables 4 and 5 . The (+) sign represents explanatory variables with positive significant t-statistics. Moreover, the overall model across the income levels was observed to have medium goodness of fit (GoF) for both models and the scale parameter.

The calibrated scale parameter for the TCB model of the low-income class is presented in Table 4 and the dummy variables for age and having a driving license were observed to have significant positive contributions to monthly TCB. This means older people and those with driving licenses are likely to spend more on daily travel due to their use of the private mode of transportation such as motorcycle or car. Moreover, monthly income was also discovered to have a significant positive influence on TCB and this means the limited income earned by low-class households affects their daily travel expenditure by limiting the amount they can spend on transportation.

The male dummy variable in the medium-high income class showed a statistically significant negative contribution to TCB and this is associated with the fact that males are less likely to spend their share of income compared to their female counterparts. Moreover, monthly income was also found not to have effects on TCB, and this shows households with high income possibly have a buffer to their source of income, thereby, lessening the burden for their travel expenditure.

\begin{tabular}{lcccc}
\hline \multirow{2}{*}{ Variable } & \multicolumn{2}{c}{ Low Income (N=180) } & \multicolumn{2}{c}{ All Data (N=450) } \\
\cline { 2 - 5 } & Coef. & Sig. & Coef. & Sig. \\
\hline Male Dummy 1, Otherwise 0 & - & - & -0.112 & 0.000 \\
Age & 0.016 & 0.080 & - & - \\
Income (million IDR/month) & 0.045 & 0.013 & 0.078 & 0.000 \\
Housing owned dummy, & -0.071 & 0.029 & - & - \\
Otherwise 0 & & & & - \\
Has Driving License & 0.205 & 0.001 & - & - \\
Dummy 1, Otherwise 0 & & & & \\
Number of Owned Vehicle & 0.073 & 0.001 & 0.142 & 0.000 \\
Travel Cost & - & - & -0.091 & 0.002 \\
\hline Number of Samples (N) & \multicolumn{2}{c}{180} & \multicolumn{2}{c}{450} \\
Adj. R square & \multicolumn{2}{c}{0.61} & \multicolumn{2}{c}{0.64} \\
F test (Sig.) & $56.51(0.000)$ & $210.44(0.000)$ \\
\hline
\end{tabular}

Table 4. Calibrated Parameter of TCB for Low Income Class.

\begin{tabular}{|c|c|c|c|c|}
\hline \multirow[t]{2}{*}{ Variable } & \multicolumn{2}{|c|}{$\begin{array}{c}\text { Medium-high } \\
\text { Income }(\mathrm{N}=270)\end{array}$} & \multicolumn{2}{|c|}{$\begin{array}{l}\text { All Data } \\
(\mathrm{N}=450)\end{array}$} \\
\hline & Coef. & Sig. & Coef. & Sig. \\
\hline Male Dummy 1, Otherwise 0 & -0.142 & 0.025 & -0.112 & 0.000 \\
\hline Age & - & - & - & - \\
\hline Income (million IDR/month) & - & - & 0.078 & 0.000 \\
\hline $\begin{array}{l}\text { Housing owned dummy, } \\
\text { Otherwise } 0\end{array}$ & -0.071 & 0.029 & - & - \\
\hline $\begin{array}{l}\text { Has Driving License } \\
\text { Dummy } 1 \text {, Otherwise } 0\end{array}$ & - & - & - & - \\
\hline Number of Owned Vehicle & - & - & 0.142 & 0.000 \\
\hline Travel Cost & - & - & -0.091 & 0.002 \\
\hline Number of Samples (N) & \multicolumn{2}{|c|}{270} & \multicolumn{2}{|c|}{450} \\
\hline Adj. R square & \multicolumn{2}{|c|}{0.65} & \multicolumn{2}{|c|}{0.64} \\
\hline F test (Sig.) & \multicolumn{2}{|c|}{$169.94(0.000)$} & \multicolumn{2}{|c|}{$210.44(0.000)$} \\
\hline
\end{tabular}

Table 5. Calibrated Parameter of TCB for Medium-high Income Class.

\section{CONCLUSION}

The results showed the average TCB for low-income households is estimated at 1.62 million IDR/month or $21 \%$ of monthly income while the medium-high income is approximately 4.3 million IDR/month or $31 \%$. The Trans Koetardja users were observed to have an average high TCB percentage close to $32 \%$. Moreover, the average ATP across income groups was estimated at 10,000 IDR/trip while the lowincome household was approximately 7,000 IDR/trip and medium-high income had a higher value reaching 12,000 IDR/month. It is, therefore, possible to define the bus tariff according to the ATP recorded for each income group and the amount recommended to be considered by the government as the average ATP is 10,000 IDR/trip (0.68 USD/trip). This means the government needs to maintain a subsidy of $3,000 \mathrm{IDR} /$ trip ( $0.2 \mathrm{USD} /$ trip) for low-income households while students should be allowed to enjoy the service free of charge. 
The linear regression analysis showed the TCB was significantly related to the variables of age, monthly income, owning a house, owning a driving license, and the number of vehicles owned for low-income households. This is observed from the fact that older people and people with driving licenses were found to be spending more money on travel than those using public transport. Moreover, monthly income was also discovered to have a significant positive influence on TCB as indicated by the restriction in the daily travel expenditure of low-income households due to their limited income while no effect was found on the TCB of medium-high income groups. This shows households with high income possibly have a buffer to their source of income and this lessens the burden for their travel expenditure.

The linear regression analysis applied in determining the TCB as well as the household budget method was able to determine an average constrained allocation of money within the household income aggregation. Therefore, they have the ability to estimate an appropriate bus fare based on the Ability to Pay (ATP) and can also assist practitioners, particularly in emerging cities. Moreover, the information on household monthly expenditure and the ATP is expected to provide insight for policymakers to understand the monetary constraints in deciding the fare to charge for the bus system.

\section{Acknowledgement}

The authors express their honest gratitude to Universitas Syiah Kuala for providing financial support for this study under Contract No. 270/UN11/SPK/PNBP/2020 and also appreciate the students for the substantial help provided with the data collection. The authors also claim all remaining oversight in this study.

\section{REFERENCES}

Adris, A.P., Jinca, M.Y., Bambang, R., Agus, T. M. (2014). The Satisfaction Analysis for the Performance of Public Transport Urban Areas. International Refereed Journal of Engineering and Science, 3(8), 38-44.

Aggraini, R., Sugiarto, S., Pramanda, H. (2017). Factors Affecting Trip Generation of Motorcyclist for the Purpose of Non-mandatory Activities. AIP Conference Proceedings, 1903(1), 060011. https://doi.org/10.1063/1.5011565

Jenkins, D.G., Quintana-Ascencio, P.F. (2020). A Solution to Minimum Sample Size for Regressions. PLoS ONE 15(2): e0229345. https://doi.org/10.1371/journal.pone.0229345

Joewono, T.B., Kubota, H. (2007). User Perception of Private Paratransit Operation in Indonesia. Journal of Public Transportation, 10(5), 99-118. http://doi.org/10.5038/23750901.10.4.5

Nursyamsu, H. (2018). Performance Level Analyses of Public Transportation using Importance-Performance Analysis Method. MATEC Web of Conferences, 147, 02001. https://doi. org/10.1051/matecconf/201814702001

Ortuzar, J de Dios., Willumsen, LG. 2011. Modelling Transport fourth Edition. John Wiley \& Sons, Ltd.

Saleh, S.M., Sugiarto, S., Hilal, A,. Ariansyah, D. (2017). A Study on the Traffic Impact of the Road Corridors due to Flyover Construction at Surabaya Intersection, Banda Aceh of Indonesia. AIP Conference Proceedings, 1903(1), 06005. https://doi.org/10.1063/1.5011559

Saleh, S. M., Sugiarto, S., Anggraini, R. (2019a). Analysis on Public's Response Toward Bus Reform Policy in Indonesia Considering Latent Variables. The Open Transportation Journal, 13, 17-24. http://dx.doi.org/10.2174/1874447801913010017

Saleh, S. M., Sugiarto, S., Salmannur, A. (2019b). Attitudinal Dataset for Mediating the Effects of Public Acceptance on Bus Reform Scheme in a Developing Country Context. Data in Brief, 25 (104035), 1-10. https://doi.org/10.1016/j.dib.2019.104035
Sekaran, U., Bougie, R. (2016). Research Methods for Business. Seventh Edition. John Wiley \& Sons Ltd.

Sugiarto, S., Miwa, T., Sato, H., Morikawa T., (2014a). Congestion Charging: Influence of Public Consciousness on Acceptability in Jakarta Metropolitan Area. Proceedings of 21st World Congress on Intelligent Transport Systems, Vol. 12914.

Sugiarto, S., Miwa, T., Sato, H., Morikawa T. (2014b). Transportation Expenditure Frontier Models in Jakarta Metropolitan Area. Procedia-Social and Behavioral Sciences. 138, 148-158. https://doi.org/10.1016/j.sbspro.2014.07.190

Sugiarto, S., Saleh, S.M., (2019). Investigating Public Perceptions and Its Implication toward Trans Koetardja oetaradja Policy Considering Latent Motivation. IOP Conf. Series: Materials Science and Engineering, 523, 012036. https://doi. org/10.1088/1757-899X/523/1/012036

Sugiarto, S., Miwa, T., Sato, H., Morikawa, T. (2020). The Tendency of Public's Attitudes to Evaluate Urban Congestion Charging Policy in Asian Megacity Perspective: Case a Study in Jakarta, Indonesia. Case Studies on Transport Policy, 8(1), 143-152. https://doi.org/10.1016/j.cstp.2018.09.010

Sugiarto, S., Lulusi., L., Mutiawati, C., Saleh, S. M., A'yuni Q., Iskandar, I. (2020b). An Exploration of Factor Affecting Household's Travel Cost Budget Considering Household Life Stages Applying to Urban Bus Ridership. Aceh International Journal of Science and Technology, 9(1), 12-21.

Tosa, C., Sato, H., Morikawa, T., Miwa, T. (2018a). Commuting Behavior in Emerging Urban Areas: Findings of a RevealedPreferences and Stated-Intentions Survey in Cluj-Napoca, Romania. Journal of Transport Geography, 68, 78-93. https://doi.org/10.1016/j.jtrangeo.2018.02.011

Tosa, C., Mitrea, A., Sato, H., Morikawa, T., Miwa, T. (2018b). Economic Growth and Urban Metamorphosis: A Quarter Century of Transformations within the Metropolitan Area of Bucharest. Journal of Transport and Land Use, 11(1), 273-295. https://doi.org/10.5198/jtlu.2018.1242

Washington, S., Karlaftis, M.G., Mannering, F., Anastasopoulos, P. 2020. Statistical and Econometric Methods for Transportation Data Analysis Third Edition, CRC Press. 